\title{
Chapter 18 \\ The State of Fisheries and Marine Species in Fukushima: Six Years After the 2011 Disaster
}

\author{
Nobuyuki Yagi
}

\begin{abstract}
The recovery of Fukushima fisheries remains sluggish 6 years after the disaster. The Fukushima Fisheries Cooperative Association (FCA) decided to allow limited fishing in June 2012 (known as the trial operation). Total landing value of fish and fishery products from the trial operation has been gradually increasing due to the increased number of catchable target species and increased fishing areas. But the landing value in 2016 was only $5 \%$ of the value recorded in the pre-disaster years. Safety of the products has been demonstrated by various surveys conducted by the government authorities and independent researchers. Several studies indicated that the population of key fish species in Fukushima waters showed a tangible increase after the 2011 disaster reflecting low fishing pressures in this period. Weak consumer confidence would have contributed to the extremely slow recovery of Fukushima fisheries. In addition to the consumers' attitudes, fish distributors' risk-averse attitudes could have brought additional adverse effects against the recovery of Fukushima fisheries. This situation could continue for several more years. Continued support for fishers in Fukushima is needed for the foreseeable future to sustain the livelihood of small fishing households as well as maintain societies, traditional knowledge, and other human or social capital in the region.
\end{abstract}

Keywords Consumer confidence $\cdot$ Fishery $\cdot$ Fukushima $\cdot$ Radiocesium $\cdot$ Tsunami

\subsection{Introduction}

The tsunami triggered by the Great East Japan Earthquake on March 11th, 2011 damaged around 29,000 fishing boats and 319 fishing ports in Japan (Fisheries Agency of Japan 2017). These numbers account for some $10 \%$ of the respective national totals. Periodical updates on the recovery status of fisheries in the Tsunamidamaged area have been provided by the Fisheries Agency of the Japanese Ministry

\footnotetext{
N. Yagi $(\bowtie)$

Graduate School of Agricultural and Life Sciences, The University of Tokyo, Tokyo, Japan

e-mail: yagi@fs.a.u-tokyo.ac.jp
} 
of Agriculture, Forestry and Fisheries (MAFF). According to the most recent report, approximately 18,486 of those boats and all ports (i.e., 319 ports) had returned to operation as of March 31st, 2017 (Fishery Agency of Japan 2017).

Despite the unprecedented scale of the disaster, the rehabilitation of the fisheries in the tsunami-damaged areas other than Fukushima has been relatively expeditious in terms of the fishing capacity as measured in the number of boats and ports. However, Fukushima fisheries are still suffering from the large-scale release of radioactive substances from the Fukushima Dai-ichi Nuclear Power Plant operated by the Tokyo Electric Power Company (TEPCO) even 6 years after the disaster.

\subsection{Declining Level of Radiocesium Contained in Fish and Fishery Products}

On a weekly basis, the Government agencies, including the Fisheries Agency of MAFF, Fukushima prefectural government and relevant municipal authorities, examine the level of radiocesium in fish and fisheries products taken from Fukushima and its surrounding waters. Samples are collected from scientific research vessels of the Fukushima prefectural government and other research boats (http://www.pref. fukushima.lg.jp/uploaded/attachment/231539.pdf). This is not random sampling across species occurring in Fukushima waters. Rather, a large number of samples are collected and species that have past records of high concentrations of radiocesium are analyzed (http://www.jfa.maff.go.jp/j/housyanou/attach/pdf/kekka-79. pdf). Time-series changes of radioactive cesium levels contained in these samples from April 2011 to June 2017 are shown in Fig. 18.1. More than 100,000 samples were examined during this period, and the proportion of samples with over $100 \mathrm{~Bq} /$ $\mathrm{Kg}$ radiocesium decreased relatively quickly in 2011 and 2012. In and after 2015, the proportion of samples with over $100 \mathrm{~Bq} / \mathrm{Kg}$ of radiocesium was almost zero. $100 \mathrm{~Bq} / \mathrm{Kg}$ is regarded as an important threshold because the allowable level of radioactive cesium established by the Japanese government was $100 \mathrm{~Bq} / \mathrm{kg}$ for all fisheries products after April 2012 (Fisheries Agency of Japan 2014).

The declining trend of radiocesium in fish and fisheries products is consistent with independent research results published after the Fukushima disaster. Wada et al. (2013), for instance, discussed that, although the time-series trends of radioactive cesium concentrations differ greatly among taxa, habitats, and spatial distributions, higher concentrations have been observed in shallower waters, and that radioactive cesium concentrations decreased quickly or were below detection limits in pelagic fish and some invertebrates. However, in some demersal fish, ${ }^{1}$ the declining trend was much more gradual, and concentrations above the regulatory limit $(100 \mathrm{~Bq} / \mathrm{kg}$-wet weight) were frequently found, indicating continued uptake of radioactive cesium through the benthic food web (Wada et al. 2013).

\footnotetext{
${ }^{1}$ The term demersal fish means fish species living near the bottom of the sea
} 


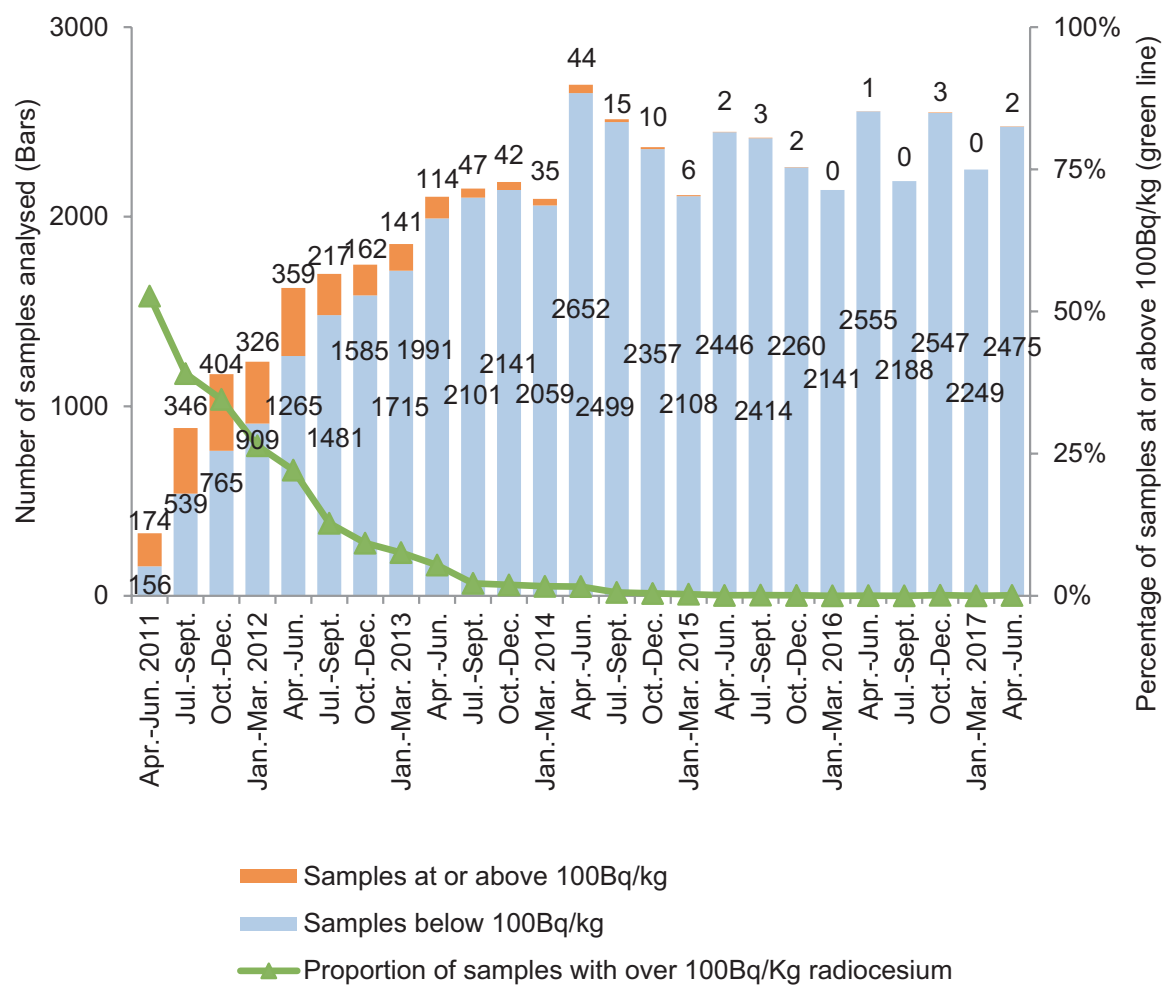

Fig. 18.1 Level of radiocesium in sampled marine organisms in Fukushima waters. (Data source: Fisheries Agency of Japan http://www.jfa.maff.go.jp/j/housyanou/kekka.html. Accessed in October 2017)

\subsection{Development of Biological Studies on Fish and Radioactive Substances}

Even before the disaster, it is widely known that the level of radiocesium concentration is different by species. For instance, according to an IAEA report (IAEA 2004), saltwater fish tend not to accumulate cesium at as high a level as freshwater fish. This mechanism can be explained as follows: in freshwater, the osmotic pressure of a fish's body fluids is higher than that of the surrounding water, and the fish actively cycle water out of their bodies while keeping salt and minerals to maintain normal levels of osmotic pressure. During this process, cesium is accumulated within the collected salt and minerals. On the other hand, the osmotic pressure in the bodies of saltwater fish is lower than that of the surrounding seawater. To prevent the loss of too much water from their bodies and to maintain balance, saltwater fish actively cycle salt and minerals - along with cesium - out of their bodies.

A more detailed mechanism of excretion of cesium from the body of fish was reported by Furukawa et al. (2012) and Kaneko et al. (2013). They reported that the 
gills of fish eliminate unnecessary cesium $\left(\mathrm{Cs}^{+}\right)$from body fluid, presumably through the same pathway as potassium $\left(\mathrm{K}^{+}\right)$excretion (Furukawa et al. 2012; Kaneko et al. 2013). Cesium is known to be a biochemical analog of $\mathrm{K}$, and through the $\mathrm{K}$ transporting pathway Cs can be released from the gills of fish (Furukawa et al. 2012; Kaneko et al. 2013).

Results of empirical studies on radiocesium concentration in various fish species are reported through a number of independent research teams after the Fukushima disaster. Kikkawa et al. (2014), using published data of 8683 samples obtained off the coast of Fukushima during the 2-year period after the disaster, identified that fish and fisheries products in Fukushima can be categorized into four groups in terms of concentration of radioactive cesium $(134 \mathrm{Cs}+137 \mathrm{Cs})$. They are (1) low concentrations of radiocesium both in 2011 and 2012, (2) some decline of concentration in 2012 but still high, (3) high initial concentrations in 2011 but levels quickly dropped and became almost undetectable in 2012, and (4) high concentration of radiocesium both in 2011 and 2012 (Kikkawa et al. 2014).

Specifically, out of 97 fish and fishery items (a total of 95 species including two species that are marketed separately for the adult and immature stages), 60 items fall in the first group (low concentration) which include invertebrate animals as well as a wide variety of vertebrate fish such as pelagic species (Kikkawa et al. 2014). The second group (some decline but still high in 2012) had 21 items and many of them are demersal species (Kikkawa et al. 2014). The third group (extremely high in 2011 but quickly reduced to undetectable levels in 2012) had 1 item, namely whitebaitsize Japanese sand lance (Ammodytes personatus) (Kikkawa et al. 2014). The fourth group (high concentration both in 2011 and 2012) had 15 items and most of them were coastal demersal vertebrate fish species such as greenling (Hexagrammos otakii) (Kikkawa et al. 2014). Consequently, Kikkawa et al. (2014) discussed that almost all the products of groups (1) and (3) satisfied the government food-safety standard as of 2012, while products in groups (2) and (4) did not satisfy the standard and must be closely monitored.

Takagi et al. (2015) reported their analyses on small epipelagic fishes (such as sardine and Japanese anchovy). Sixty-three samples were collected by commercial fishery boats off the Kashima-Boso area (approximately $100 \mathrm{~km}$ south of Fukushima waters) from March 24th, 2011 to March 21st, 2013. The radiocesium concentration in fish muscle reached a maximum of $31 \mathrm{~Bq} / \mathrm{kg}$-wet weight in July 2011, and after that, it declined gradually. From 2012 to 2013, the radiocesium concentration in fish muscle was low (0.58-0.68 Bq/kg-wet weight).

It is possible that radiocesium concentration in fish depends on the size and the age of fish. Year-class related difference in radiocesium concentrations in the body of fish was examined by Narimatsu et al. (2015). Pacific cod (Gadus macrocephalus) captured from April 2011 to March 2014 off Fukushima Prefecture were analyzed and they found the radiocesium concentration of cod in the year-class of 2009 (i.e., cod born in the year 2009) and earlier was higher than that in the 2010 year-class. In addition, radiocesium was rarely detected or detected at very low levels in the 2011 year-class. Regression analyses showed that the estimated ecological half-life of radiocesium in Pacific cod was from 258 to 309 days; this value is consistent with 
values in other demersal fish caught off Fukushima Prefecture as reported by Wada et al. (2013). Narimatsu et al. (2015) further pointed out that the half-life was longer in old and larger individuals than in young and smaller individuals, probably a result of differences in metabolic rate and growth rates between age and body size classes as proposed in the study of Doi et al. (2012). Radiocesium was rarely detected in the 2011 year-class, most likely because the fish were only exposed to very low levels of radiocesium when they started their life in the ocean bottom and after that radiocesium in the fish body was diluted by growth (Narimatsu et al. 2015).

\subsection{Limited Resumption of Fishing in Fukushima Waters}

In Fukushima, a total of 873 fishing vessels were damaged by the tsunami on March 11th, 2011 (Ministry of Agriculture, Forestry and Fisheries, Japan 2012). After March 12th, the large-scale release of radioactive substances from the Fukushima Dai-ichi Nuclear Power Plant occurred. On March 15th, 2011, the Fukushima Prefectural Federation of Fisheries Cooperative Association (hereafter referred to as the Fukushima FCA) voluntarily stopped fishing operations in the waters inside of Fukushima Prefecture (Yagi 2014, 2016). Some fishing activities in the prefectures neighboring Fukushima (namely Miyagi and Ibaraki) were also suspended after the Fukushima disaster, but most of these were subsequently lifted within 2 years (Ibaraki Prefecture 2014; Miyagi Prefecture 2014). Neither the national nor the prefectural governments revoked fishing licenses in Fukushima (Yagi 2016). However, the national government did provide legally binding sales prohibitions on certain marine products caught in the waters off Fukushima Prefecture based on food safety requirements (Yagi 2016).

After a cessation of fishing for more than 1 year, the Fukushima FCA decided to resume fishing activities in June 2012, hereafter referred to as the 'trial operation', for three species (two octopus species and one shellfish species) living at depths of more than 150 meters in ocean areas approximately $60-90 \mathrm{~km}$ from the damaged nuclear power plant (Yagi 2014, 2016). The trial operation has several limitations, and therefore it is not regarded as a full resumption of commercial fishing. The limitations include: (i) days of operation (usually fewer than 5 days a month); (ii) landing ports (only two ports have been designated: one in Soma City and the other in Iwaki City); (iii) the amount of landed fish (usually less than 10 tons a day); and (iv) the number of vessels involved in fishing operations (Yagi 2014). Operation rules are set to maintain a high frequency of monitoring for radioactive substances and to ensure traceability following the landing of marine products (Yagi 2016). Most of these products were sold at local supermarkets in Fukushima, and sold out very quickly, most likely due to the small number of available items and consumers wishing to help their local fishers by purchasing their products (Yagi 2014).

The Fukushima FCA monitored for radiocesium at the two landing sites (namely, Soma-Futaba and Iwaki) from the start of the trial operation. Analyses were carried out for every species landed during the day of each trial operation. $0.5-1.0 \mathrm{~kg}$ of 
edible parts is randomly taken as a representative sample of each species on the day, and radiocesium $\left({ }^{134} \mathrm{Cs}\right.$ and ${ }^{137} \mathrm{Cs}$ combined) is measured using $\mathrm{NaI}$ scintillation counters installed at the two landing sites. Landed fish have been sold with labels indicating Fukushima as their point of origin (Yagi 2014).

As of May 2017, the trial operation has caught approximately 20-40 species and, therefore, all these species have been measured for radiocesium. The level of radiocesium in samples are reported on the website of the Fukushima FCA, and all records from 2012 until today are available (http://www.fsgyoren.jf-net.ne.jp/kensakekka201209.pdf for Soma-Futaba landing site and http://www.fsgyoren.jf-net. ne.jp/kensakekka-iwaki.pdf for Iwaki landing sites). In almost all samples, the level of radiocesium was below $12.5 \mathrm{~Bq} / \mathrm{kg}$ and such results are reported as "not detected" on the websites.

The legally binding sales prohibition by the government has been periodically revised. Since December 2013, the prohibition has been in effect for 40 marine species living in the waters of Fukushima (Fukushima Prefecture 2014), and since January 2015, it has been reduced to 35 species (Fukushima Prefecture 2015). As of October 11th, 2017, the number of species subject to the sales prohibition was reduced to 10 marine species (Fukushima Prefecture 2017a). These species are not allowed to land by the trial operation.

Total landing value of fish and fishery products from the trial operation has gradually increased due to the increased number of catchable species and increased fishing areas. But its landing value in 2016 was still at the level of 1/20 of the predisaster years. The total value of fish and fishery products landed in Fukushima from the trial operation was 461 million JPY (approximately 4 million USD) in 2016, while the value of landed fish and fishery products in 2009 and 2010 was 11,280 million JPY and 10,959 million JPY (both values are equivalent to approximately 100 million USD), respectively (Fukushima Prefecture 2017b, for predisaster data, and post-disaster data through personal communications with $\mathrm{Mr}$. Noguchi of the Fukushima FCA).

\subsection{Weak Consumer Confidence and Risk-Averse Distributers}

Weak consumer confidence, along with the limited fishing (i.e., limited number of fishing boats and fishing days), could have contributed to the extremely slow pace of recovery of Fukushima fisheries. Consumer attitudes in Japan toward agricultural and fishery products have been reported by various researchers since the 2011 disaster. Aruga (2017), for instance, examined consumer attitudes in Japan for seven agricultural products (rice, apples, cucumbers, beef, pork, eggs, and shiitake mushrooms) from regions near the Fukushima Daiichi nuclear power plant. It was found that consumers with children under the age of 15 required a higher discount rate to accept agricultural products from regions near the power plant (Aruga 2017). Conversely, consumers who trusted the current safety standards for radioactive 
material concentrations in food were more likely to purchase products from regions near the plant (Aruga 2017). As for fishery products, Wakamatsu and Miyata (2017) studied consumers' evaluation of Pacific cod (Gadus macrocephalus) and whitebait (Engraulis japonicus) and found that the calculated values of consumers' marginal willingness to pay dropped for products originating from Fukushima compared with products originating from other parts of Japan.

In addition to consumers' attitudes, fish distributors' risk-averse attitudes could have brought additional adverse effects against the recovery of Fukushima fisheries. Even though some consumer segments are interested in Fukushima products, such products cannot be delivered to the consumers if distributors avoid trading such products. Fishers have no choice but to accept risk-averse attitudes of distributors or retailors, because fishers are in a weaker position. In the case of Japan's fishery distribution, the market power rests with retail stores rather than producers even before the Tsunami in 2011 (Sakai et al. 2012; Nakajima et al. 2014). In Fukushima after 2011, fishers' market power was weakened further. While fishing activities are geographically linked to specific marine areas designated by fishing licenses, processing or distribution industries are under no such administrative requirements. These industries can move from Fukushima and still continue their business in fish distribution and processing. In fact, some large fish processing facilities in the disaster-affected region decided to relocate their factories outside of these areas, and they still have not returned to the region. Although no systematic study has been conducted on the attitudes of fish distributors and retailers against Fukushima food products, various news reports suggested that risk-averse food distributors could exist and they may have adversely affected the recovery of agriculture and fisheries in Fukushima (for instance, NHK TV broadcast on May 24th, 2017. https://www. nhk.or.jp/gendai/kiji/fukushima/. Accessed October 2017).

\subsection{Increased Abundance of Key Target Fish Species in Fukushima}

The population of key fish species in Fukushima waters showed a tangible increase after the 2011 disaster reflecting low fishing pressures from 2011 to 2014. Narimatsu et al. (2017) reported that the population of Pacific cod (Gadus macrocephalus) inhabiting waters off northeastern Honshu, Japan, which includes all Fukushima waters, has increased in 2012, 2013, and 2014 after the Great East Japan Earthquake in 2011. Their research suggests that Pacific cod increased post-2011 not because of the occurrence of strong year classes followed by good recruitments but because of the lower mortality after recruitment owing to reduced fishing mortality in the Fukushima area.

Shibata et al. (2015) also reported that the result of their analysis based on a fish population model suggested that abundance of sea ravens (Hemitripterus villosus) off Fukushima increased after the 2011 accident. Shibata et al. (2017) further reported 
that, based on the analysis of their fish population model, the abundance of Japanese flounder (Paralichthys olivaceus) on and after 2012 increased owing to the decreased fishing effort during this period. These study outcomes are consistent with oral reports received from Fukushima fishers. The author is a member of the "Fukushima Prefectural Fisheries Reconstruction Committee" which was established by Fukushima FCA in 2012 with the aim of reconstructing the fisheries industry and restarting fisheries operations (Yagi 2014). The committee has repeatedly discussed conditions of fish stocks and fishers recognized increased populations of Pacific cod or some other species during their trial operation after mid-2012.

\subsection{Conclusion}

Fukushima fisheries are slow to recover after 6 years since the disaster occurred. The Fukushima FCA had stopped fishing since March 15th, 2011 and, after a series of internal discussions, it decided to reopen limited fishing in June 2012 (i.e., trial operation). Total landing value of fish and fishery products from the trial operation has been gradually increasing due to the increased number of catchable target species and increased fishing areas. But its landing value in 2016 was still only 5\% of the value recorded in the pre-disaster years.

Safety of the products has been demonstrated by various surveys. More than 100,000 samples were examined from April 2011 to June 2017 by government authorities, and the proportion of samples with over $100 \mathrm{~Bq} / \mathrm{Kg}$ radiocesium decreased relatively quickly in 2011 and 2012. In and after 2015, the proportion of samples with over $100 \mathrm{~Bq} / \mathrm{Kg}$ of radiocesium decreased to almost zero. Several studies indicated that the population of key fish species in Fukushima waters showed a tangible increase after the 2011 disaster reflecting low fishing pressures from 2011 to 2014.

But the reality is that the recovery of fishery productions has been sluggish. Weak consumer confidence may have contributed to the extremely slow pace of recovery of Fukushima fisheries. Fish distributors' risk-averse attitudes could have brought additional adverse effects against the recovery of Fukushima fisheries. This situation could continue for several more years judging from the fact that production shortfalls in Fukushima fisheries can be easily offset with products from other Japanese regions or foreign countries. Before the disaster in 2011, Fukushima fisheries produced only $1 \%$ of Japan's marine products. ${ }^{2}$ Fukushima's share of the Japanese market is even lower when we consider that about half of the marine products consumed in Japan are imported from overseas. In other words, meeting the requirements of the Japanese consumer can be fulfilled without using products from Fukushima. The export of seafood from Japan, in particular products from Fukushima and the surrounding waters, is subject to strict import restrictions or

\footnotetext{
${ }^{2}$ Author's calculation using the data in Fisheries Agency of Japan (2017) and Fukushima Prefecture (2017b).
} 
prohibitions by various countries. Under these circumstances, continued help for Fukushima fishers is required for several more years to sustain the livelihood of small fishing households as well as maintain societies, traditional knowledge, and other human or social capital in the region.

Acknowledgement The author acknowledges Mr. Kazunobu Noguchi of the Fukushima FCA for his support in data compilation of the trial operation.

\section{References}

Aruga K (2017) Consumer responses to food produced near the Fukushima nuclear plant. Environ Econ Policy Stud 19:677-690. https://doi.org/10.1007/s10018-016-0169-y

Doi H, Takahara T, Tanaka K (2012) Trophic position and metabolic rate predict the long-term decay process of radiocesium in fish: a meta-analysis. PLoS One 7:e29295. https://doi. org/10.1371/journal.pone.0029295

Fisheries Agency of Japan (2014) Questions and Answers on fisheries. Website accessed in February 2014. http://www.jfa.maff.go.jp/j/kakou/Q_A/index.html (in Japanese)

Fisheries Agency of Japan (2017) The Great East Japan Earthquake's impact on fisheries and future measures. July 2017 (in Japanese)

Fishery Agency of Japan (2017) White paper on fisheries (in Japanese)

Fukushima Prefecture (2014) Website of fisheries division, Fukushima Prefecture. http://wwwcms.pref.fukushima.jp/pcp_portal/PortalServlet. Accessed Feb 2014 (in Japanese)

Fukushima Prefecture (2015) Discussion material for "Fukushima Prefectural Fisheries Reconstruction Committee" Materials prepared by Fukushima Prefecture and distributed to the press and committee members on January 22, 2015

Fukushima Prefecture (2017a) Website of Fisheries Division, Fukushima Prefecture. http://www. pref.fukushima.lg.jp/uploaded/attachment/222247.pdf. Accessed Oct 2017 (in Japanese)

Fukushima Prefecture (2017b) Catch Statistics of Fukushima marine capture Fisheries https:// www.pref.fukushima.lg.jp/sec/36035e/suisanka-toukei-top.html. Accessed Oct 2017 (in Japanese)

Furukawa F, Watanabe S, Kaneko T (2012) Excretion of cesium and rubidium via the branchial potassium-transporting pathway in Mozambique tilapia. Fish Sci 78:597-602

Ibaraki Prefecture (2014) Restricted items for marketing and distributions as of February 21, 2014. http://www.pref.ibaraki.jp/nourin/gyosei/housyanou_jyouhou.html\#4. Accessed Feb 2014 (in Japanese)

International Atomic Energy Agency (2004) Sediment distribution coefficients and concentration factors for biota in the marine environment, Technical report 422. IAEA, Vienna

Kaneko T, Furukawa F, Watanabe S (2013) Excretion of cesium through potassium transport pathway in the gills of a marine teleost. In: Nakanishi TM, Tanoi K (eds), Agricultural implications 105 of the Fukushima nuclear accident. https://doi.org/10.1007/978-4-431-54328-2_11

Kikkawa T, Yagi N, Kurokura H (2014) The state of concentration of radioactive cesium in marine organisms collected from the Fukushima coastal area: a species by species evaluation. Bull Jpn Soc Fish Sci 80:27-33 (in Japanese)

Ministry of Agriculture, Forestry and Fisheries, Japan (2012) Basic statistical data on damages in agriculture, forestry and fisheries caused by the Great East Japan Earthquake. http://www.maff. go.jp/j/tokei/joho/zusetu/pdf/00_2406all.pdf. Accessed Jan 2015 (in Japanese)

Miyagi Prefecture (2014) Restricted items for marketing and distributions as of February 18, 2014. http://www.pref.miyagi.jp/uploaded/attachment/245220.pdf. Accessed Feb 2014 (in Japanese) 
Nakajima T, Matsui T, Sakai Y, Yagi N (2014) Structural changes and imperfect competition in the supply chain of Japanese fisheries product markets. Fish Sci 80:1337-1345

Narimatsu Y, Sohtome T, Yamada M, Shigenobu Y, Kurita Y, Hattori T, Inagawa R (2015) Why do the radionuclide concentrations of Pacific cod depend on the body size? In: Nakata K, Sugisaki $\mathrm{H}$ (eds) Impacts of the Fukushima nuclear accident on fish and fishing grounds. Springer Open, Tokyo

Narimatsu Y, Shibata Y, Hattori T, Yano T, Nagao J (2017) Effects of a marine-protected area occurred incidentally after the great East Japan earthquake on the Pacific cod (Gadus macrocephalus) population off northeastern Honshu Japan. Fish Oceanogr 26:181-192

Sakai Y, Nakajima T, Matsui T, Yagi N (2012) Asymmetric price transmission in Japanese seafood market. Nippon Suisan Gakkaishi 78:468-478 (in Japanese)

Shibata Y, Yamada M, Wada T et al (2015) A surplus production model considering movements between two areas using spatiotemporal differences in CPUE: application to sea ravens Hemitripterus villosus off Fukushima as a practical marine protected area after the nuclear accident. Mar Coast Fish 7:325-337

Shibata Y, Sakuma T, Wada T, Kurita Y, Tomiyama T, Yamada M, Iwasaki T, Mizuno T, Yamanobe A (2017) Effect of decreased fishing effort off Fukushima on abundance of Japanese flounder (Paralichthys olivaceus) using an age-structured population model incorporating seasonal coastal-offshore migrations. Fish Oceanogr 26:193-207

Takagi K, Fujimoto K, Watanabe T, Kaeriyama H, Shigenobu Y, Miki S, Ono T, Morinaga K, Nakata K, Morita T (2015) Radiocesium concentration of small epipelagic fishes (sardine and Japanese anchovy) off the Kashima-Boso area. In: Nakata K, Sugisaki H (eds) Impacts of the Fukushima nuclear accident on fish and fishing grounds. Springer Open, Tokyo

Wada T, Nemoto Y, Shimamura S, Fujita T, Mizuno T, Sohtome T, Kamiyama K, Morita T, Igarashi S (2013) Effects of the nuclear disaster on marine products in Fukushima. J Environ Radioact 124:246-254

Wakamatsu H, Miyata T (2017) Reputational damage and the Fukushima disaster: an analysis of seafood in Japan. Fish Sci 83:1049-1057

Yagi N (2014) The state of fishing industry in Fukushima after the nuclear power-plant accident. Glob Environ Res 18:65-72

Yagi N (2016) Impacts of the nuclear power plant accident and the start of trial operations in Fukushima fisheries. In: Nakanishi T, Tanoi K (eds) Agricultural implications of the Fukushima nuclear accident. Springer, Tokyo, pp 217-227

Open Access This chapter is licensed under the terms of the Creative Commons Attribution 4.0 International License (http://creativecommons.org/licenses/by/4.0/), which permits use, sharing, adaptation, distribution and reproduction in any medium or format, as long as you give appropriate credit to the original author(s) and the source, provide a link to the Creative Commons license and indicate if changes were made.

The images or other third party material in this chapter are included in the chapter's Creative Commons license, unless indicated otherwise in a credit line to the material. If material is not included in the chapter's Creative Commons license and your intended use is not permitted by statutory regulation or exceeds the permitted use, you will need to obtain permission directly from the copyright holder.

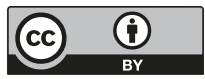

